\title{
Bulletin
}

\section{of the Americtall}

Metedrologiteal

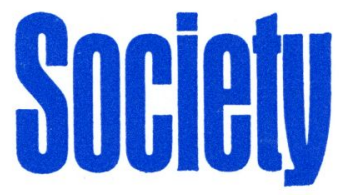

Volume 58 Number 6 June 1977

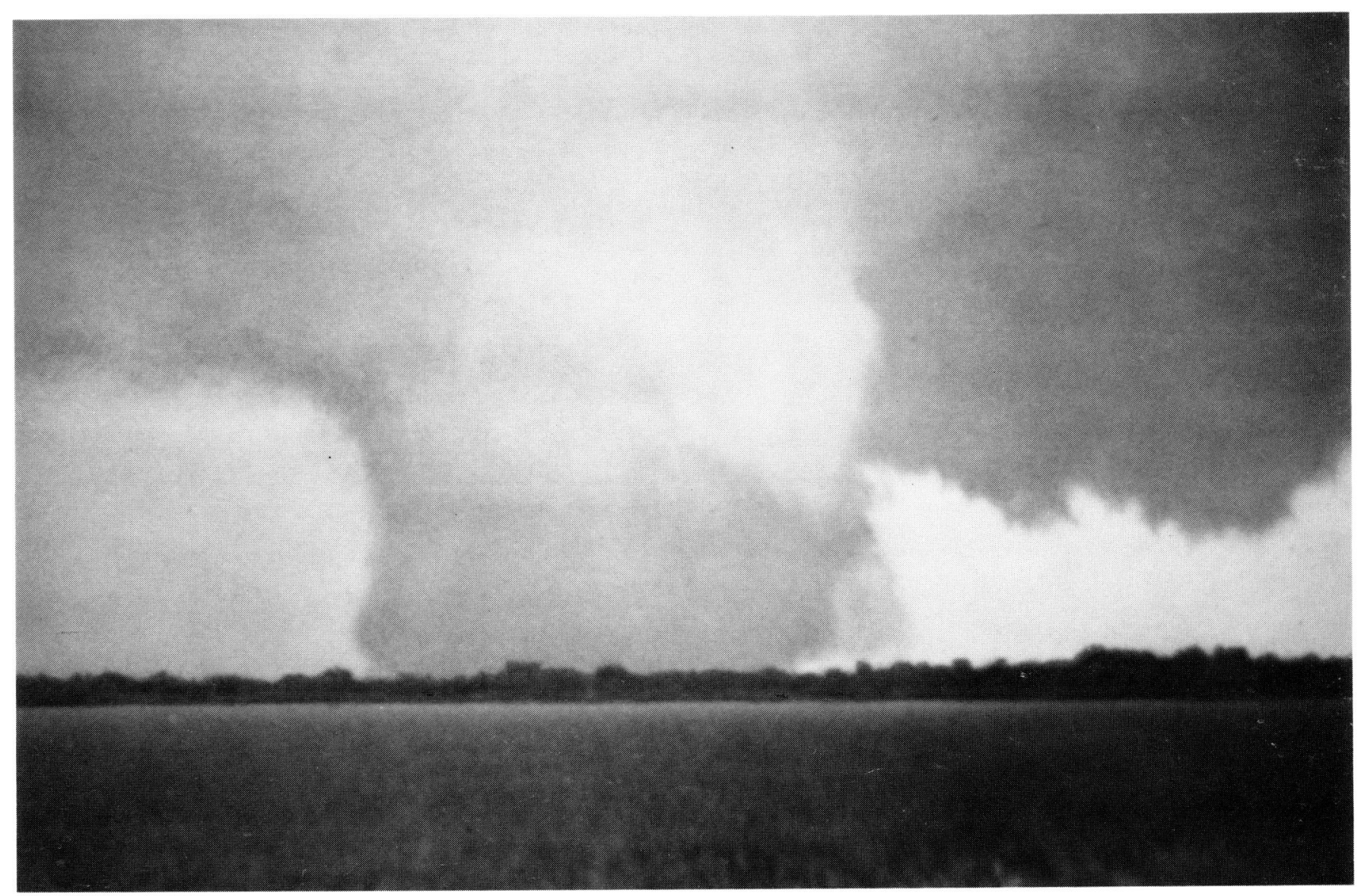




\section{ARE YOU ENERGY-ORIENTED?}

If you're looking for answers-in the wind, sun, or water-we can help you select instruments that will meet your technical specifications and your budget.

Write for our revised literature. Many sections-all part of Catg. No. 9-have been completed.

Sect. 1 Temperature

2 Humidity

3 Pressure

4 Wind

5 Precipitation

6 Solar Radiation

7 Upper Air \& Visibility

More sections are in preparation.

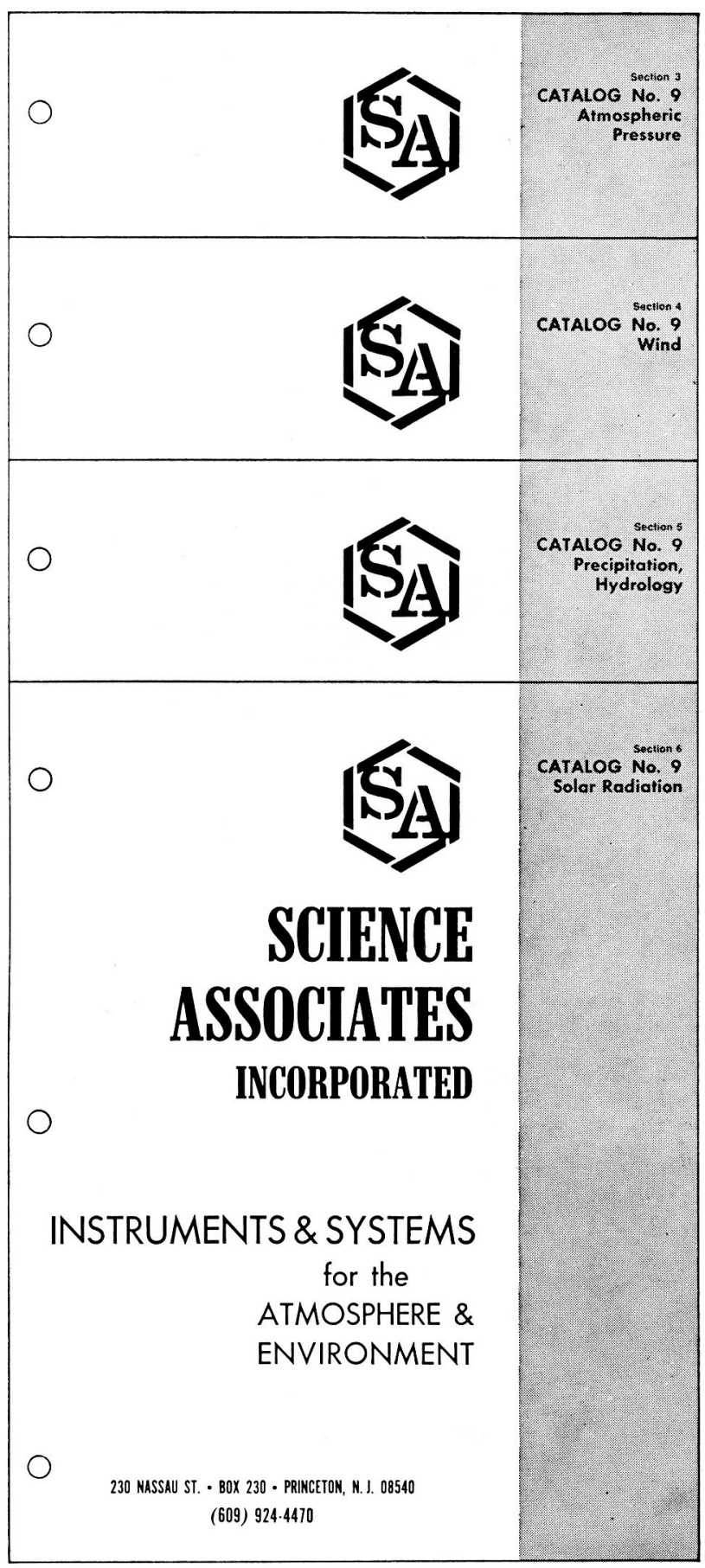




\section{Continuous GOES picture printout}

$\uparrow$ 03:00 22SE76 13A-Z 0006-1640 FULL IISC IR



\section{...for the cost of a private phone line}

You can now receive dramatic GOES (Geostationary Environmental Satellite) sectors generated from the full earth disc such as this through a service provided to your local Weather Service Forecast Office.

Infrared and visible GOES pictures, covering major portions of the United States, are transmitted at intervals throughout the day and can be received on ALDEN 1800 and ALDEN 1100 Facsimile Recorders.

Phone companies at the various Weather Service Forecast Office locations will furnish the GOES signal to all external users who apply to the National Weather Service Headquarters for an agreement. This provides a valuable service at a considerably lower cost than was previously available.

Pictures received on the ALDEN 1800 are large...18 inches wide by any transmitted length and contain up to 16 tone shades of useful discernible information. Pictures are seen as they are printed...no waiting for complete picture and post picture processing.
The ALDEN Facsimile Recorders provide unequaled reliability and unattended operation and are backed by the ALDEN name and a nationwide service organization.

To learn more, fill out the coupon or call the ALDEN Sales Department at 617/366-8851.

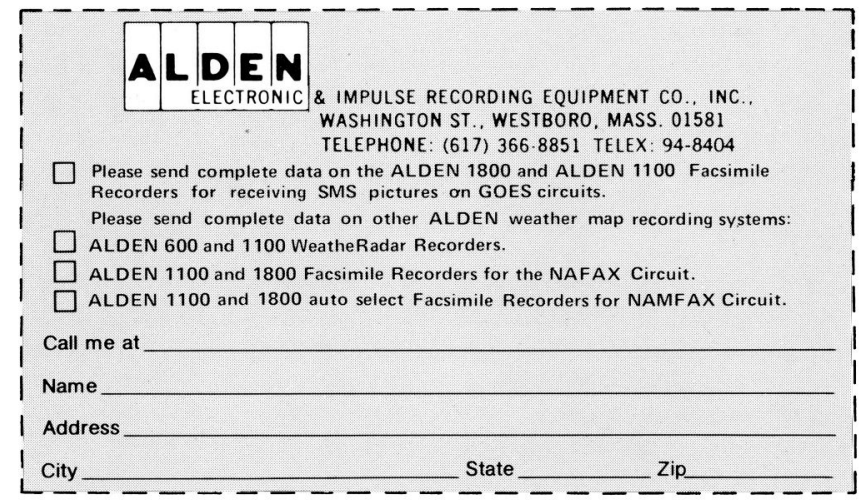

\section{ALDEN...THE FIRST NAME IN WEATHER CHART/PICTURE RECORDERS.}




\section{Rainfall Measuring Instruments}

CAT. NO. 5-780

SERIES

UNIVERSAL

RECORDING

RAIN GAGES

Bulletin $76-3$

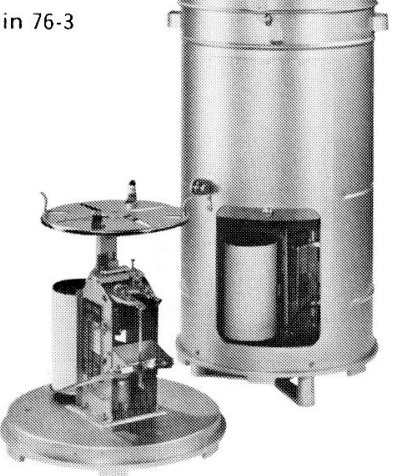

$1 / 2$ of $1 \%$ F.S. dual-traverse accuracy over $-40^{\circ}$ to $+125^{\circ} \mathrm{F}$

$6^{\prime \prime} \mathrm{ST}, 4.8^{\prime \prime}, 12^{\prime \prime}, 20^{\prime \prime}, 300 \mathrm{~mm}$, and $500 \mathrm{~mm}$ DT ranges

All but $5-780-20,-500 \mathrm{MM} \ldots \ldots . \$ \$ 435.00$ 5-780-20, -500MM w/overflow. . 480.00 FOB Balto., Md.
HIGH-CAPACITY, RECORDING PRECIPITATION GAGES,

CAT. NO. 6071 SERIES

Bulletin 76-80

$11.314^{\prime \prime} \mathrm{dia}$.

teflon-

coated

collector

ruggedized

weighing

mechanism

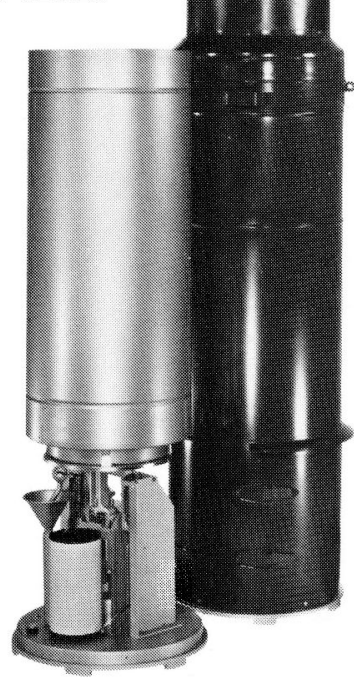

30 " and $750 \mathrm{~mm}$ dual-traverse capacities $1 / 2$ of $1 \%$ F.S. accuracy, dual-traverse, over range of $-40^{\circ}$ to $+125^{\circ} \mathrm{F}$.

$\$ 825.00$ Balto., Md
CAT. NO. 5-405

UNHEATED

AND

5-405HA

HEATED

TIPPING

BUCKET

RAIN

GAGES

Bulletin $76-44$
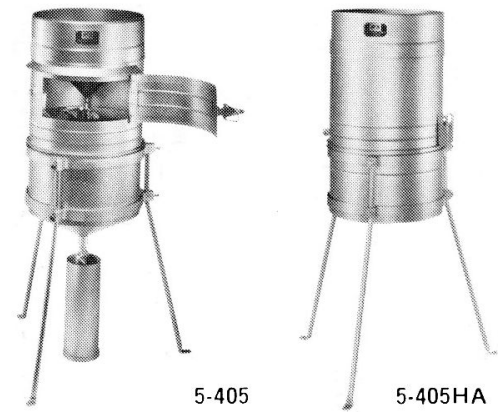

$1-6 \%$ accuracies over 1.6 in. per hour rainfall rates

$0.01^{\prime \prime}$ and $0.2 \mathrm{~mm}$ sensitivit. are available

Cat. No. 5-405HA Rain Gages are insulated and heated for operation down to $-20^{\circ} \mathrm{F}$.

Cat. No. 5-405.... \$425.00

Cat. No. $5 \cdot 405$ HA . $\quad 530.00$ FOB, Balto., Md.

\begin{tabular}{|c|c|}
\hline Write fc & ur free complete Instrument Catalog. \\
\hline 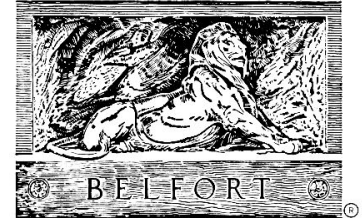 & $\begin{array}{l}\text { BELFORT INSTRUMENT COMPANY } \\
1600 \text { S. CLINTON STREET } \\
\text { BALTIMORE, MARYLAND } 21224 \text { U.S.A. } \\
\text { Tel: (301)-342-2626 }\end{array}$ \\
\hline
\end{tabular}


Bullelifin

of the American Meterpologiteal Socilell

Editor

Kenneth C. Spengler

Technical Editor

James E. Caskey, Jr.

News Editor

Janet P. Dockery

Copy Editor

Reine Rosenbaum

Meetings Editor

Evelyn Mazur

Assistant Meetings Editor

Twila A. Bombard

Advertising

Lilly G. Albo

The Bulletin of the American MeteoroLOGICAL SOCIETY is the official organ of the Society, devoted to editorials, survey articles, professional and membership news, announcements, and Society activities. Editing and publishing are under the direction of Kenneth C. Spengler, Executive Director. Members are encouraged to send to the Society information that they wish to be considered for publication. Four copies of each manuscript (text and illustrations) are required. For guidance on preparation and style, see "Information for Contributors" on inside covers of a recent issue of any AMS research journal.

AMS Officers and Councilors: President, Werner A. Baum; President-Elect, George P. Cressman; Executive Director, Kenneth C. Spengler Secretary-Treasurer, David F. Landrigan; Past Presidents, David Atlas and Charles L. Hosler, Jr.; and Councilors: Stanley A. Changnon, Jr., Neil L. Frank, Francis S. Johnson, Paul W. Kadlec, Albert J. Kaehn, Jr., Roy L. Leep, Jr., Margaret A. LeMone, Frederick P. Ostby, Jr., Norman A. Phillips, Frederick Sanders, Joanne Simpson, Robert W. Stewart, David K. Todd, Robert M. White, Jay S. Winston.

Published monthly by the American Meteorological Society at 45 Beacon St., Boston, Mass. 02108. Second-class postage paid at Boston Mass., and at additional mailing offices. Subscription price to members is included in annual dues ( $\$ 20$ per year). The subscription price to nonmembers is available on request; single issues are $\$ 5$ each. Address all business communications, purchase orders, and inquiries regarding the Society to the Executive Director, American Meteorological Society, 45 Beacon St., Boston, Mass. 02108 (617-227-2425).

(C) Copyright 1977 by the American Meteorological Society.

articles

Digital Satellite Imagery in Industrial Meteorology

C. L. Bristor and W. L. Raynore

Environmental Impacts of Precipitation Management: Results and Inferences from Project Skywater . . . . . . . . . W. E. Howell

\section{correspondence}

Record Storms and Flood over the Red River Valley, June-July 1975 . . . . . . . . . . . . . . . . . . . . . . . . . . . . . R. Jensen

Hydraulic Jump in Thunderstorm Outflow

P. H. Hildebrand

Micas, Epitaxy, Snowflakes, and Cloud Formation

STAC scientific review

An Overview of Recent Work in Weather Forecasting and Suggestions for Future Work . . . . . . . . . . R. A. Pielke

public policy affairs

Climatic Variation Research-Example of NSF Activities in the Astronomical, Atmospheric, Earth, and Ocean Sciences:

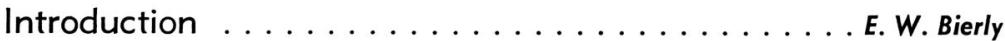

Statement before the House Subcommittee on Science,

Research, and Technology, 8 February 1977 ... . . E. P. Todd

program

Second Conference on Hydrometeorology . . . . . . . . . . . . . .

announcements 487

ICAS items 526

book reviews 528

news and notes 532

about our members

540

necrology

542

news from our chapters ...... 543

at AMS headquarters ...... 548

corrigendum

548
AMS announces undergraduate awards and scholarships ... 550

AMS notice: 1977 nominating committee report ....... 551

lists of new members . . . . . . 552

calendar of meetings ....... 554

contents of AMS journals .... 572

corporation members ........ 576

professional directory . . ..... 577

index to advertisers . . . . . . 586

Cover photograph: Tornado funnel from storms that occurred over the Red River Valley in June-July 1975. The funnel was $\backsim 1600 \mathrm{~m}$ across at the bottom, and a thunderous roar accompanied it. A secondary funnel was trying to develop on the right side of the huge main funnel. (Photo taken at about 4:30 p.m. (CDT) on 28 June 1975 by Roger Jensen.) For more details, see correspondence by Jensen on p. 502. 